\title{
The Effects of Different Strength Training on Static and Dynamic Balance Ability of Volleyball Players
}

\author{
Mehmet Ali Eylen ${ }^{1}$, Onder Daglioglu ${ }^{1}$, Erkan Gucenmez ${ }^{1}$ \\ ${ }^{1}$ Gaziantep University, School of Physical Education and Sports, Gaziantep, Turkey \\ Correspondence: Onder Daglioglu, Gaziantep University, School of Physical Education and Sports, Gaziantep, Turkey.
}

Received: December 11, 2017

Accepted: December 19, 2017 Online Published: December 23, 2017

doi:10.11114/jets.v5i13.2881

URL: https://doi.org/10.11114/jets.v5i13.2881

\begin{abstract}
The aim of this study is to examine the effect of different strength training on the static and dynamic balance ability of volleyball players. A total of 20 male volleyball players, aged between 18 and 25, are participated in the study who has been playing in national volleyball competition in Gaziantep. The subjects were divided into two groups according to the randomized method as experimental group $(\mathrm{n}=10$, age:21.60 \pm 2.06$)$ and control group $(\mathrm{n}=10$, age:20.50 \pm 1.77$)$. The experimental group was given a different strength training program for 3 days a week for 8 weeks. Both groups continued their regular volleyball practice. Leg strength, static and dynamic balance measurements were made before starting the different strength training in both groups and after the training was finished. Takei Leg Dynamometer used for leg strength measurement and Biodex Balance SD Isokinetic Balance Test for balance measurement. Paired Sample $t$ test was used for intra-group comparisons and Independent Sample t test was used for statistical analysis of the data. When the pre-test and post-test measurements of the experimental group were compared, there were significant differences in leg strength, static (Double leg-Overall Postural Stability Index (OPSI), Right Leg-OPSI, Left Leg-OPSI) and dynamic (Right Leg- Overall Stability Index (OSI), Left Leg-OSI) balance scores $(\mathrm{p}<0.05)$. The control group showed significant significance in the Double leg-OPSI score $(\mathrm{p}<0.05)$. No other significance was found in the other data $(\mathrm{p}>0.05)$. As a result, it is considered that the different strength training applied to the volleyball players has a positive effect on the static and dynamic balance ability. It can be said that static and dynamic balance abilities of regular strength training may increase.
\end{abstract}

Keywords: strength training, balance, volleyball

\section{Introduction}

The main aim of all sports branches is to develop the physical characteristics required for that sport in a continuous harmony and to improve the performance of the sportsmen. Balance can be defined as the ability to hold the origin of the body. Maintaining balance is the basis of the complex interaction among visual functions and coordination of movements with muscle activity (Emery, 2003; Horak, 1987). There are basically two types of balance, static and dynamic. Static stability, stable state means protection. Dynamic balance is to maintain balance while moving. Balance control is a fundamental requirement for sports, daily activities and sports (Anderson \& Behm, 2005). The athletes' balance capabilities in different sports branches bring about different challenges in biomedical competence. . For this reason, the balance test becomes necessary to determine how these athletes perform in the balance test (Bressel, 2007). The volleyball branch is a team sport including complex movements and requiring constantly moving and versatile skills. Therefore, important physical features such as balance, endurance, reaction speed, explosive force, and quick force are emerging as characteristics that should be found in volleyball players (Wulf, 2007; Siedentop, 2011). The element that provides the presentation of many physical or sportive movements, and stopping, changing direction, moving, moving sports equipment, and having a constant body position is balance. Proprioceptive senses also play an important role in the maintenance and protection of the body's balance. Proprioception is a special sense including sense of joint motion and feeling of joint position (Lephart, 1997). The element that provides the presentation of many physical or sportive movements, and stopping, changing direction, moving, moving sports equipment, and having a constant body position is balance. In the light of this information, it was planned to investigate the effect of different strength trainings on the static and dynamic balance ability of volleyball players in this study. Considering the effect of strength and balance development on the sportive performance, changes in leg strength, and static and dynamic balance scores after different strength training in volleyball players were determined and it is aimed to be able to make suggestions for sportsman, coach and sports science. 


\section{Method}

\subsection{Subjects}

A total of 20 male volleyball players between the ages of 18 and 25 participated in the national competition in the province of Gaziantep as volunteers. Subjects were randomly divided into two groups as experimental group ( $\mathrm{n}=10$, age: $21.60 \pm 2.06)$ and control group $(n=10$, age: $20.50 \pm 1.77)$. The experimental group was given a different strength training program for 3 days a week for 8 weeks. Both groups continued their regular volleyball training. Information indicating that the research is appropriate for the ethics committee was informed to Gaziantep University Clinical Research Ethics Committee Presidency and Ethics Committee Approval was obtained.

\subsection{Research Protocol}

In order to reveal the anthropometric properties of individuals; age, body weight, height and body mass index (BMI) were measured. Leg strength in individuals was measured with the Takei Leg Dynamometer and static and dynamic balance scores with the Biodex Balance SD Isokinetic Balance Test. Before the experiment and control group started to work on different strengths and after finishing the work, static (Double leg-Overall Postural Stability Index (OPSI), Right Leg-OPSI, Left Leg-OPSI) and dynamic (Right Leg-Overall Stability Index (OSI), Left Leg-OSI) balance scores and leg strength were measured. Measurements were made in Physiology Laboratory of Gaziantep University Physical Education and Sports High School.

\subsection{Strength Training Model}

As a method of strength training, Core Training, leg curl, leg extensions, squat, pliometric bounce, single leg lunge, split squat jump, deadlift, double leg bound movements were applied in unit training. Bench press and shoulder press exercises were used as auxiliary muscles. In the Core Trainer, Russian Twist and Side Plank exercises were performed.

Standard weights of 2,5 - 5 - 7,5 - 10 - 12,5 - 15 - 20 - $25 \mathrm{~kg}$ are used for bench press, shoulder press, leg curl, leg extensions and squat measurement. The maximal forces of the subjects were determined by the one-repetition max (1 $\mathrm{RM})$. The volleyball players in the experimental group were subjected to different strength training sessions on the 1st and 3rd day of the week, with 3 sets of 8 repetitions (maximal strength training) and 3 sets of 20 repetitions (strength endurance training). In the Core training, Russian Twist and Side Plank movements were applied to 15 sets of 1st and 3 rd day and 15 sets of 3 rd set and 25 sets of 3 sets of 2 nd day. The strength training applied to the experimental group lasted for an average of 30 minutes and the athletes were given a warm-up period of 10-15 minutes before the training.

\subsection{Anthropometric Measurements}

Anthropometric measurements of the subjects joined to the study were measured before exercise tests. Body weight and height were determined by using the tool with N.A.N brand. Subjects' body mass indexes (BMI) were calculated. BMI measurements were calculated by dividing the body length of the body in meters of length.

\subsection{Balance Test}

Balance tests were performed using the Biodex Balance System (Biodex Balance System, BBS; Biodex Inc., Shirley, NY), which can accurately reflect the balance performance.

Static test: Performed on right leg, left leg and posture positions on Double leg respectively. At the fixed point on the screen from the test during the static test; it is desirable to keep it stable by trying to maintain the balance to the front, back, right, left. The tests were repeated 3 times with a duration of 20 seconds and a rest interval of 10 seconds and scores were recorded.

Dynamic test: In our work, the dynamic test was performed on the right and left leg positions, respectively. Level 4 dynamic balance test was used in this study. The tests were repeated 3 times with a duration of 20 seconds and a rest interval of 10 seconds and scores were recorded.

\subsection{Leg Strength Test}

In our study, leg strength measurements were made using the Takei Leg Dynamometer. After the subjects had placed their legs bent over the dynamometer stand, the dynamometer held by their hands with their backs straight and tilted forward with their arms straight and taut, pulled all the power from their legs in the vertical position. The same procedure was repeated 3 times and the highest score was recorded.

\subsection{Data Analysis}

Statistical analyzes of this study were performed using the SPSS statistical program (SPSS for Windows, version 20.0, SPSS Inc. Chicago, Illinois, USA). The Shapiro-Wilk test was performed to determine whether the data were normally distributed and homogeneous before proceeding to statistical procedures. The Independent Samples T Test was used to assess the significance between the experimental and control groups. Paired Samples T Test was run for intra-group comparisons. Statistical results were evaluated at $95 \%$ confidence interval and $\mathrm{p}<0.05$ significance level. 


\section{Results}

Table 1. Experiment and Control Group Age, Height, Weight and BMI Average

\begin{tabular}{ccc}
\hline Variable & $\begin{array}{c}\text { Experimental Group } \\
\text { Mean } \pm \mathrm{SD}\end{array}$ & $\begin{array}{c}\text { Control Group } \\
\text { Mean } \pm \mathrm{SD}\end{array}$ \\
\hline Age (years) & $21.60 \pm 2.06$ & $20.50 \pm 1.77$ \\
Height $(\mathrm{cm})$ & $181.90 \pm 5.23$ & $180.80 \pm 2.25$ \\
Weight $(\mathrm{kg})$ & $72.49 \pm 2.16$ & $74.30 \pm 2.18$ \\
BMI $\left(\mathrm{kg} / \mathrm{m}^{2}\right)$ & $21.93 \pm 0.99$ & $22.73 \pm 0.80$ \\
\hline
\end{tabular}

In Table 1, presents the supplementary statistical information of the groups. The average age of the experimental group was $21.60 \pm 2.06$ years and the average age of the control group was $20.50 \pm 1.77$ years. Body weight was measured as $72.49 \pm 2.16 \mathrm{~kg}$ for the experimental group and $74.30 \pm 2.18 \mathrm{~kg}$ for the control group. The height of the experimental group was measured as $181.90 \pm 5.23 \mathrm{~cm}$ while that of the control group was measured as $180.80 \pm 2.25 \mathrm{~cm}$. BMI values were found to be $21.93 \pm 0.99 \mathrm{~kg} / \mathrm{m}^{2}$ in the experimental group and $22.73 \pm 0.80 \mathrm{~kg} / \mathrm{m}^{2}$ in the control group.

Table 2. Analysis of Pre and Post Test Static and Dynamic Balance Scores of Experimental Group

\begin{tabular}{cccccc}
\hline Variable & $\begin{array}{c}\text { Pre Test } \\
\text { Mean } \pm \text { SD }\end{array}$ & $\begin{array}{c}\text { Post Test } \\
\text { Mean } \pm \text { SD }\end{array}$ & df & t & p \\
\hline Leg Strength & $130.60 \pm 11.86$ & $132.70 \pm 11.38$ & 9 & -4.523 & $\mathbf{0 . 0 0 1 *}$ \\
Double leg-OPSI & $0.44 \pm 0.14$ & $0.34 \pm 0.10$ & 9 & 4.743 & $\mathbf{0 . 0 0 1}^{*}$ \\
Right Leg-OPSI & $0.83 \pm 0.13$ & $0.77 \pm 0.16$ & 9 & 2.714 & $\mathbf{0 . 0 2 4}$ \\
Left Leg-OPSI & $0.92 \pm 0.21$ & $0.62 \pm 0.13$ & 9 & 4.108 & $\mathbf{0 . 0 0 3 *}$ \\
Right Leg-OSI & $0.92 \pm 0.24$ & $0.67 \pm 0.16$ & 9 & 3.273 & $\mathbf{0 . 0 1 0}$ \\
Left Leg-OSI & $0.87 \pm 0.09$ & $0.75 \pm 0.09$ & 9 & 4.811 & $\mathbf{0 . 0 0 1 *}$ \\
\hline
\end{tabular}

$*(\mathrm{p}<0.05)$ (OPSI: Overall Postural Stability Index), (OSI: Overall Stability Index)

In Table 2, comparison of the pre-test and post-test measurement results for the parameters given after the different strength training program applied to the experimental group were shown. The leg strength, static and dynamic balance scores of the experimental group were significant $(\mathrm{p}<0.05)$.

Table 3. Analysis of Static and Dynamic Balance Scores of The Control Group

\begin{tabular}{cccccc}
\hline Variable & $\begin{array}{c}\text { Pre Test } \\
\text { Mean } \pm \text { SD }\end{array}$ & $\begin{array}{c}\text { Post Test } \\
\text { Mean } \pm \text { SD }\end{array}$ & df & t & p \\
\hline Leg Strength & $130.46 \pm 5.98$ & $131.90 \pm 5,34$ & 9 & -1.881 & 0.093 \\
Double leg-OPSI & $0.40 \pm 0.14$ & $0.34 \pm 0.11$ & 9 & 3.674 & $\mathbf{0 . 0 0 5 *}$ \\
Right Leg-OPSI & $0.84 \pm 011$ & $0.82 \pm 0.13$ & 9 & 0.802 & 0.443 \\
Left Leg-OPSI & $0.96 \pm 0.12$ & $0.95 \pm 0.17$ & 9 & 0.287 & 0.780 \\
Right Leg-OSI & $0.95 \pm 0.17$ & $0.89 \pm 0.15$ & 9 & 1.765 & 0.111 \\
Left Leg-OSI & $0.92 \pm 0.09$ & $0.89 \pm 0.11$ & 9 & 1.152 & 0.279 \\
\hline
\end{tabular}

$*(\mathrm{p}<0.05)$ (OPSI: Overall Postural Stability Index), (OSI: Overall Stability Index)

In Table 3, comparison of pre-test and post-test measurement results for the parameters given after the different strength training program applied to the control group were shown. Significance was found in the double leg-OPSI scores of the control group $(p<0.05)$. No other significance was found in the other data ( $p>0.05)$. 
Table 4. Comparison of Experimental and Control Groups

\begin{tabular}{cccccc}
\hline Variable & $\begin{array}{c}\text { Experimental } \\
\text { Group Difference } \\
\text { Mean } \pm \text { SD }\end{array}$ & $\begin{array}{c}\text { Control Group } \\
\text { Difference } \\
\text { Mean } \pm \text { SD }\end{array}$ & df & $\mathrm{t}$ & $\mathrm{p}$ \\
\hline Leg Strength & $-2.10 \pm 1.46$ & $-1.44 \pm 2.42$ & 18 & -0.737 & 0.471 \\
Double leg-OPSI & $0.10 \pm 0.06$ & $0.06 \pm 0.05$ & 18 & 1.500 & 0.151 \\
Right Leg-OPSI & $0.06 \pm 0.06$ & $0.02 \pm 0.07$ & 18 & 1.200 & 0.246 \\
Left Leg-OPSI & $0.30 \pm 0.23$ & $0.01 \pm 0.11$ & 18 & 3.585 & $\mathbf{0 . 0 0 2 *}$ \\
Right Leg-OSI & $0.25 \pm 0.24$ & $0.06 \pm 0.10$ & 18 & 2.273 & $\mathbf{0 . 0 3 6}$ \\
Left Leg-OSI & $0.12 \pm 0.07$ & $0.03 \pm 0.08$ & 18 & 2.496 & $\mathbf{0 . 0 2 2}$ \\
\hline
\end{tabular}

$*(\mathrm{p}<0.05)$ (OPSI: Overall Postural Stability Index), (OSI: Overall Stability Index)

In Table 4, there was significant difference between the groups in the Left Leg-OPSI, Right Leg-OSI, Left Leg-OSI in favor of the experimental group ( $\mathrm{p}<0.05)$. Leg strength, Double leg-OPSI, Right Leg-OPSI didn't show any significance $(\mathrm{p}>0.05)$.

\section{Discussion}

\subsection{Static Balance Test}

After 8 weeks of different strength training applied in our study, a significant difference was found in the scores of Double leg-OPSI, Right Leg-OPSI, Left Leg-OPSI in the experimental group, and Double leg-OPSI in the control group ( $p<0.05)$. There was no significant difference between Right Leg-OPSI and Left Leg-OPSI scores of the control group (p>0.05). In the comparison of the groups, statistically significant difference was found in the Left Leg-OPSI in favor of the experimental group (Table 4).

Balance is one of the main elements of most physical activities and an important factor in the performance of sports skills. Punakallio defined the static balance as the ability to hold the press in the support center in the middle (Abbasi et al., 2012). The general balance data is important when volleyball players leap and fall during training or match.

Tamara et al. found static balance values to be significant compared to the control group after 6 weeks of training program on female basketball players (Tamara, 2009). Holm et al have not found any significant difference in the static balance scores after a disability preventive exercise program on a handball group of 35 people (Holm et al., 2004). In a study on young basketball players, it was determined that there was a difference in the positive direction after pre-test and post-test on the balance abilities after the plyometric training (Arazi \& Asadi, 2011).

The findings in our study showing that there was a positive decrease in the scores Double leg-OPSI, Right Leg-OPSI and Left Leg-OPSI in favor of the experimental group after the different strength training program applied to volleyball players supports the literature.

\subsection{Dynamic Balance Test}

A significant difference was found in the Right Leg-OSI and Left Leg-OSI scores in the experimental group after 8 weeks of different strength training applied in our study $(\mathrm{p}<0.05)$, but any significant association was not found when the parameters of the control group were analyzed ( $p>0.05$ ). In the comparison of the groups, a statistically significant difference was found in the Right Leg-OSI, Left Leg-OSI scores in favor of the experimental group (Table 4).

Most of the daily activities are performed dynamically, so dynamic balance is extremely important in the realization of physical activities and sports skills (Abbasi et al., 2012). Mattacola and Lloyd (1997) conducted training on resistance to ankle and dynamic balance in an exercise. Participants received both balance and force training. have found that power training is effective to maintain the balance measured by the Single Plane Balance Board (Mattacola \& Lloyd, 1997). In a study on athletes, an 8-week balance exercise resulted in an increase in lower extremity muscle strength and balance ability (Siriphorn, 2015).

Kahle (2009) found that core muscle stability training can improve dynamic postural control in a study of the effects of 6-week core muscle stability training (Kahle, 2009).

It is thought that the significant difference in the dynamic balance scores of the Right Leg-OSI and Left Leg-OSI of the experimental group in dynamic balance measurements in our study was due to the strength training of the players together with volleyball training. It can be said that the increases in balance and leg strengths are caused by the exercises performed in volleyball trainings in which the dominant and non-dominant feet are equally used. 


\subsection{Leg Strength}

A significant increase was found in the leg strength values of the experimental group after 8 weeks of different strength trainings in our study $(\mathrm{p}<0.05)$. The increase in the control group was not found statistically significant $(\mathrm{p}>0.05)$. There was no significant difference in the comparison of the groups.

In a study in which the effects of Tai Chi Softball (TCSB) exercises on body functions of elderly individuals were examined, TCSB exercise was found to be effective on physical properties like leg strength, dynamic balance, mobility, fine motor function and control, hand and forearm muscle strength, claw strength and shoulder mobility (Lin et al., 2017). In another study conducted on judoists, significant differences were found in leg strength values (Karakoc, 2016). In the study performed by Perez-Turpin et al., leap performance and maximum leg strength of well-trained volleyball and beach volleyball players were observed to improve significantly as a result of 6-week Whole Body Vibration (WBV) exercise, ie whole body vibration force exercise, when compared to conventional training alone (Perez-Turpin et al., 2014). In the literature, the general belief is that leg strength values increase after strength training. Our findings of leg strength values after different strength trainings in the experimental and control groups in our study support the literature. It can be said that 8 -week different strength trainings significantly affected the leg strength values of the volleyball players.

As a result; it can be said that the different strength trainings applied to volleyball players affected the static and dynamic balance scores positively. It can be deduced that increased static and dynamic balance abilities of players performing strength trainings is due to increase in working capacities of intermuscular and intramuscular muscle groups due to increase in muscle strength. For the development of performance and balance in volleyball, it can be suggested that the strength exercises are given considerable place in the training period and different strength exercise programs are generated.

\section{Acknowledgements}

This study is a part of Mehmet Ali EYLEN's master thesis. We thank our Department of Physical Education and Sport in University of Gaziantep for their support in our study.

\section{References}

Abbasi, A., Tabrizi, H., Sarvestani, H., \& Rahmanpourmoghaddam, J. (2012). Dynamic Balance In Inactive Elder Maleschanges After Eight Weeks Functional and Core Stabilization Training, Middle-East Journal Of Scientific Research, 11(3), 304-310.

Anderson, K. G., \& Behm, D. G. (2005). The impact of instability resistance training on balance and stability. Sports Medicine, 35(1), 43-53. https://doi.org/10.2165/00007256-200535010-00004

Arazi, H., \& Asadi, A. (2011).The Effect of Aquatic and Land Plyometric Training on Strength, Sprint, and Balance in Young Basketball Players. Journal of Human Sport \& Exercise, 6(1). https://doi.org/10.4100/jhse.2011.61.12

Bressel, E., Yonker, J. C., Kras, J., \& Heath, E. M. (2007). Comparison of static and dynamic balance in female collegiate soccer, basketball, and gymnastics athletes. J. Athl. Train., 42, 42-46.

Emery, C. A. (2003). Is there a clinical standing balance measurement appropriate for use in sports medicine? A review of the literature. Journal of Science and Medicine in Sport, 6(4), 492-504. https://doi.org/10.1016/S1440-2440(03)80274-8

Holm, I., Fosdahl, M. A., Friis, A., Risberg, M. A., Myklebust, G., \& Steen, H. (2004). Effect of Neuromuscular Training on Proprioception, Balance, Muscle Strength, And Lower Limb Function in Female Team Handball Players, Clinical Journal Sport Medicine, 14, 88-94. https://doi.org/10.1097/00042752-200403000-00006

Horak, F. B. (1987). Clinical Measurement of Postural Control in Adults. Physical Therapy, 67(12), 1881-1885. https://doi.org/10.1093/ptj/67.12.1881

Kahle, N. L. (2009). Core Stability Training in Dynamic Balance Testing Among Young, Healthy Adults. Athletic Training \& Sports Health Care, 1(2), 65-73. https://doi.org/10.3928/19425864-20090301-03

Karakoc, O. (2016). Muscle Strength and Flexibility without and with Visual Impairments Judoka's, International Education Studies; 9(5). https://doi.org/10.5539/ies.v9n5p12

Lephart, S. M., Princivero, D. M., Giraldo, J. L., \& Fu, F. H. (1997). The Role of Proprioception in The Management and Rehabilitation of Athletic Injuries. The American Journal of Sports Medicine, 25, 130-137. https://doi.org/10.1177/036354659702500126 
Lin, L., Liye, Z., Fang, Q., Wrang, H., Liu, Y., Tian, Z., \& Han, Y. (2017). Effect of Taichi Softball On Function-Related Outcomes in Older Adults. A Randomized Control Trial, Evid. Based Complement Alternat. Med., https://doi.org/10.1155/2017/2186987

Mattacola, C. G., \& Lloyd, J. W. (1997). Effects of a 6-week strength and proprioception training program on measures of dynamic balance: A single case design. Journal of Athletic Training, 32(2), 127-135.

Perez-Turpin, J. A., Zmijewski, P., Jimenez-Olmedo, J. M., Jove-Tossi, M. A., Suarez-Llorca, C., \& Andreu-Cabrera, E. (2014). Effects of Whole Body Vibration on Strength and Jumping Performance in Volleyball and Beach Volleyball Players. Biology of Support, 31(3), 239-244. https://doi.org/10.5604/20831862.1112435

Siedentop, D., Hastie, P. A., \& Van der Mars, H. (2011). Complete Guide to Sport Education. $2^{\text {nd }}$ ed. USA: Human Kinetics.

Siriphorn, A., \& Chamonchant, D. (2015). Wii balance board exercise improves balance and lower limb muscle strength of overweight young adults, J. Phys. Ther. Sci., 27, 41-46. https://doi.org/10.1589/jpts.27.41

Tamara, C., Mcleod, V., Armstrong, T., Miller, M., \& Sauers, J. L. (2009). Balance Improvements in Female Highschool Basketball Players After A 6 Week Neuromuscular-Training Program. Journal of Sport Rehabilitation, 18, 465-481. https://doi.org/10.1123/jsr.18.4.465

Wulf, G. (2007). Attention and Motor Learning. Human Kinetics, Champaign, IL, 2007.

\section{Copyrights}

Copyright for this article is retained by the author(s), with first publication rights granted to the journal.

This is an open-access article distributed under the terms and conditions of the Creative Commons Attribution license which permits unrestricted use, distribution, and reproduction in any medium, provided the original work is properly cited. 